This is a postprint version of the following published document:

B.L. Boada, M.J.L. Boada, V. Díaz (2016). Vehicle sideslip angle measurement based on sensor data fusion using an integrated ANFIS and an Unscented Kalman Filter algorithm. Mechanical Systems and Signal Processing, 72-73. Pp. 832-845.

http://dx.doi.org/10.1016/i.ymssp.2015.11.003

(C) Elsevier 2016

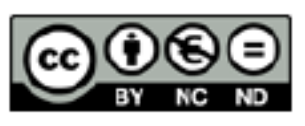

This work is licensed under a Creative Commons Attribution-NonCommercialNoDerivatives 4.0 International License. 


\title{
Vehicle sideslip angle measurement based on sensor data fusion using an integrated ANFIS and an Unscented Kalman Filter algorithm
}

\author{
B.L. Boada ${ }^{1}$, M.J.L.Boada and V. Diaz \\ Mechanical Engineering Department, Research Institute of Vehicle Safety (ISVA), \\ Universidad Carlos III de Madrid. Avenida de la Universidad, 30 Leganés (Madrid), \\ Spain
}

\begin{abstract}
Most existing ESC (Electronic Stability Control) systems rely on the measurement of both yaw rate and sideslip angle. However, one of the main issues is that the sideslip angle cannot be measured directly because the sensors are too expensive. For this reason, sideslip angle estimation has been widely discussed in the relevant literature. The modeling of sideslip angle is complex due to the non-linear dynamics of the vehicle. In this paper, we propose a novel observer based on ANFIS, combined with Kalman Filters in order to estimate the sideslip angle, which in turn is used to control the vehicle dynamics and improve its behavior. For this reason, low-cost sensor measurements which are integrated into the actual vehicle and executed in real time have to be used. The ANFIS system estimates a "pseudo-sideslip angle" through parameters which are easily measured, using sensors equipped in actual vehicles (inertial sensors and steering wheel sensors); this value is introduced in UKF in order to filter noise and to minimize the variance of the estimation mean square error. The estimator has been validated by comparing the observed proposal with the values provided by the CARSIM model, which is a piece of experimentally validated software. The advantage of this estimation is the modeling of the non-linear dynamics of the vehicle, by means of signals which are directly measured from vehicle sensors. The results show the effectiveness of the proposed ANFIS+UKF-based sideslip angle estimator.
\end{abstract}

\section{Introduction}

With the recent advancements in the vehicle industry, driving safety in passenger vehicles is considered to be one of the key issues in the design of any vehicle. Electronic Stability Control (ESC) is seen as the greatest road safety innovation since the seatbelt. Hence, the market demands more research in order to improve performance of these systems.

To improve vehicle handling and stability based on ESC, the yaw rate, that is, the yaw velocity of the chassis, and the vehicle sideslip angle, the angle between the directions of the vehicle's velocity and its chassis, are controlled so that they follow their target values $[1,2]$. The yaw rate can be directly measured by a yaw rate sensor (gyroscope) $[3,4]$. In addition, the sideslip angle can be directly measured via optical or GPS sensors [5-7]. However, the drawbacks of measuring the yaw rate and the sideslip angle have to do with the accuracy, reliability and cost [8]. Sideslip angles cannot be directly measured using standard sensors, therefore, the measurements must be estimated by means of an observer

\footnotetext{
${ }^{1}$ Corresponding author: bboada@ing.uc3m.es
} 
[9-11]. For this reason, an accurate estimation of the vehicle's sideslip angle is essential for applications in vehicle dynamics and control.

Sideslip angle estimation has been widely discussed in the literature. The modeling of sideslip angles is complex due to the non-linear dynamics of the vehicle. Some authors employ physical models for the estimation of sideslip angles [12-15]. The most-cited methods are based on the bicycle dynamic model or its variations. These models generate noise-free sideslip angle estimations, but they can be sensitive to changes in the vehicle parameters. Other authors use kinematic based-models that consider the motion of a body, which are not affected by uncertainties [14,16,17]. These methods integrate the derivative of the sideslip angle, calculated from sensor signals including yaw rate, lateral acceleration and vehicle speed. Satisfactory robustness of tire properties, road friction and vehicle parameters, such as vehicle mass and moment of inertia, can be achieved. Finally, there are also authors who use combined methods which bring together the advantages of the previous two methods $[9,11]$.

Furthermore, some authors propose methods for designing observers in order to estimate the sideslip angle from variables that can be easily measured; such as the yaw rate, lateral acceleration and velocity. Different models, such as linear [18] and nonlinear [19], and observers such as Kalman Filters [10,20] have also been considered in order to estimate the sideslip angle. A common feature of most of these observers for the estimation of the sideslip angle is that they rely heavily on an accurate tire model, which may vary during vehicle operation.

The unscented Kalman filtering (UKF) is a powerful tool for the state estimate of nonlinear systems [21-23]. The UKF is able to achieve good performance if the complete information of measurement noise distribution is taken as known.

The major problem for estimating the sideslip angle adequately is tire non-linarites. Nowadays, different non-linear tire models are considered in order to carry out a good modeling. The Pacejka tire model [23] is one which has been taken into consideration during recent years. There are various Pacejka tire models with different degrees of complexity. In one model, which is widely used, tire forces are considered relative to both normal forces and slip, non-linear forces.

The problem is that the tire forces also depend on road conditions (icy, wet or dry road surface). Previous studies have estimated the sideslip angle assuming that the vehicle is driven on a road with the friction coefficient constant. When, the road friction coefficient changes, the vehicle dynamics also change. If the parameters of the model are not modified in the observers, the estimation of sideslip angle could be mistaken.

The disadvantage of Kalman filters-based estimators is that is that the optimality of the estimation algorithm depends on the quality of a priori knowledge of the process and measurement noise statistics.

More recently, Artificial Intelligence (AI) algorithms have been proposed in order to eliminate some of its inadequacies [24-27]. AI-based algorithms have been proved to be appropriated in order to avoid issues associated with the identification and adaptation of reference model parameters. In [28-30], AI-based algorithms are used to estimate the 
sideslip angle based on fuzzy, Neural Network (NN) and ANFIS (Adaptive Neuro-Fuzzy Inference System), respectively.

In our previous work [30], we proposed an ANFIS-based observer to estimate the sideslip angle. It proved that the ANFIS-based estimator provides an error smaller than the NNbased and Kalman-based estimators. However, the disadvantage is that AI-based methods do not use any statistical information as input, nor do they output statistics associated with the solution, unless methods of cross-validation are applied.

In this paper, we propose a novel observer based on ANFIS and combined with a Kalman Filter, in order to estimate the sideslip angle that is used to control the vehicle dynamics and improve its behavior.

Other researches also combines AI-based techniques with Kalman Filter for estimation. In this case, The IA-based algorithm is based on the improvement of the filter performance through the adaptive estimation of the filter statistical information (covariance matrices) [31-33]. The problem is that the uncertainty learning is a difficult and complex process. In this case, we do not estimate the filter statistical information but also we estimate a "pseudo-parameter", a "pseudo-sideslip angle", which is introduced in Filter Kalman.

The ANFIS system estimates a "pseudo-sideslip angle" through parameters which are easily measured using actual vehicles equipped with sensors (inertial sensor and steering wheel sensor) and this value is introduced in UKF in order to filter the noise and to minimize the variance of the mean square error estimation. The ANFIS-based observer combines the benefits of both Neural Networks and Fuzzy logic. The former is adaptive and can learn from generalization and pattern recognition. The latter allows soft and steady performance [34]. In [35], an ANFIS algorithm is proposed to estimate the yaw rate, providing good results. The advantage is that the ANFIS-observer could learn from different road conditions and maneuvers.

CarSim software has been employed to test the effectiveness of the proposed algorithm [36] and its use has become widespread as simulation software in the automotive industry. The software combines traditional and modern multi-body vehicle dynamics, based on parametric modeling. The software includes a three-part graphic database of a full-vehicle model, direction and speed control and external conditions, such as, road information, drag and so on.

CarSim results obtained after training show that the proposed observer learns to estimate the sideslip angle behavior properly and reliably, without difficulty. The efficiency of the observer is demonstrated through plentiful simulation tests.

\section{Vehicle dynamic model}

The dynamic model used in the estimation process is a 2-DOF vehicle model which consists of lateral and yaw motions. The state space equations of the model are:

- Lateral motion:

$$
m\left(\dot{V}_{y}+r V_{x}\right)=\left(F_{y f l}+F_{y f r}\right) \cos \delta+F_{y r l}+F_{y r r}
$$


- Yaw motion:

$$
I_{z} \dot{r}=a\left(F_{y f l}+F_{y f r}\right) \cos \delta-b\left(F_{y r l}+F_{y r r}\right)
$$

where, $m$ is the vehicle mass, $I_{z}$ is the moment of inertia of the vehicle, $a$ and $b$ are the distances from the center of gravity to the front and rear axles, respectively, $F_{y f i}(\mathrm{i}=\mathrm{f}, \mathrm{r}$ ) is the lateral tire force of the front wheels, $F_{y r i}(\mathrm{i}=\mathrm{f}, \mathrm{r})$ is the lateral tire force of the rear wheels, $V_{x}$ and $V_{y}$ are longitudinal and lateral velocities of $\mathrm{CG}, r$ is the yaw rate of the vehicle, and $\delta$ is the front and steering angles.

Two tire models are considered to prove the effectiveness of the proposed observer: the lineal tire model and the nonlinear tire model such as the Magic Formula of Pacejka [29].

\section{Proposed observer based on ANFIS combined with Kalman Filters}

The sideslip angle is an essential parameter whose knowledge is fundamental for vehicle controlling behavior. The sideslip angle of a vehicle $(\beta)$ is the angle between the orientation of the vehicle and the direction of travel at the center of gravity (COG). It is defined as:

$$
\beta=\arctan \frac{V_{x}}{V_{y}}
$$

The proposed observer architecture is shown in . The estimation process consists of two blocks.

The former is an ANFIS-based observer which serves to estimate the sideslip angle (pseudo-variable). The inputs to this block are the measurements of steering angle using a steering wheel sensor, lateral acceleration, longitudinal velocity and yaw rate using a combination of GPS and inertial measurement unit (IMU). The advantage of this observer is that it uses measurements of sensors which are already incorporated in current vehicles. The ANFIS-based observer gives a "pseudo-sideslip angle" which is going to be incorporated to the second block. This "pseudo-measurement" can not be used directly as input in the vehicle lateral controller due to it is affected by noise of sensors. For this reason, it is necessary the second block.

The latter is a Kalman-based observer which filters the noise of measurements obtained from the first block and the inertial sensor (IMU). In this block, the inputs are the yaw rate, which is measured by an inertial sensor, and the sideslip angle, which is obtained from an ANFIS-based observer. Both signals are used as observed data, $\mathrm{y}_{\mathrm{k}}$, in the Kalman Filter. Then, the new sideslip angle is estimated in the update phase of the Kalman Filter such that the estimation error is minimized. Different types of Kalman Filters are considered (Lineal Kalman Filter, Extended Kalman Filter and Unscented Kalman Filter) in order to prove the effectiveness of the proposed observer. 


\subsection{ANFIS}

ANFIS is a fuzzy inference system whose parameters are iteratively adjusted according to a given set of input and output data. The system is an adaptive network, functionally equivalent to a first-order Sugeno fuzzy inference system. The resultant network architecture, called ANFIS (Adaptive Neuro-Fuzzy Inference System), is shown in .

Consider a first-order Sugeno fuzzy inference with three inputs. The rules in this Sugeno model have the format:

$$
\text { if } x \text { is } A_{i} \text { and } y \text { is } B_{i} \text { and } z \text { is } C_{i} \text { then } f=\mathrm{p}_{1} \cdot x+q_{1} \cdot y+q_{1} \cdot z+r_{1}
$$

The criteria considered to select the inputs for the ANFIS algorithm are:

- To select the minimum number of inputs.

- To select signals that can be measured by onboard vehicle sensors (GPS, IMU and steering wheel sensors).

Considering the previous criteria, the following input data have been selected:

- Lateral acceleration, $\mathrm{a}_{\mathrm{y}}$.

- Steering angle, $\delta$.

- Yaw rate/Longitudinal velocity, $\left(\mathrm{r} / \mathrm{V}_{\mathrm{x}}\right)$.

Layer 1: Each node in this layer generates a membership grade of a linguistic label. Every node function of the $i$-th node is a square node with a node function:

$$
O_{i}^{1}=\mu(i)
$$

where $\mu(i)_{i}$ are MFs. In this study, a Gaussian function with a maximum equal to 1 and minimum equal to 0 is selected:

$$
O_{i}^{1}=\exp \left[-\left(\frac{x-b_{i}}{a_{i}}\right)^{2}\right]
$$

where $a_{i}$ and $b_{i}$ are the parameters that change the shapes of the membership function.

Layer 2: Each node in this layer calculates the firing strength of a rule via multiplication:

$$
O_{i}^{2}=w_{i}=\mu(i)_{i} \cdot \mu(i)_{i+1}
$$

Layer 3: Node $i$ in this layer calculates the ratio of the i-th rule's firing strength to the total of all firing strengths:

$$
O_{i}^{3}=\overline{w_{l}}=\frac{w_{i}}{w_{1}+w_{2}} \quad(i=1,2)
$$

Layer 4: Node $i$ in this layer computes the contribution of $\mathrm{i}$-th toward the overall output, with the following node function:

$$
O_{i}^{4}=\bar{w}_{l} f=\bar{w}_{l}\left(\mathrm{p}_{1} \cdot x+q_{1} \cdot y+q_{1} \cdot z+r_{1}\right)
$$


Layer 5: The single node in this layer computes the overall output as the summation of the contribution from each rule:

$$
O_{i}^{5}=\Sigma \bar{w}_{l} f=\frac{\Sigma w_{i} f}{\Sigma w_{i}}
$$

To generate the Fuzzy Logic Estimator (FLE) presented in this work, a MATLAB ANFIS toolbox was used. The neural network was generated and trained, based on the input data specified previously. The network is trained and tested in order to prevent the learning algorithm from falling into a global minimum.

The basic learning rule of ANFIS is the hybrid learning algorithm. This hybrid algorithm performs two phases at each learning stage; the first is a forward path learning technique that uses the least-squares learning technique, and the second is the back-propagation learning algorithm.

The selection of training data is a crucial process. These data should contain all of the required representative features. In this case, different maneuvers are selected in order to characterize the linear and non-linear vehicle behavior.

A total of 80 experiments were designed and carried out for J-turn maneuvers at different speeds $(30 \mathrm{~km} / \mathrm{h}, 65 \mathrm{~km} / \mathrm{h}, 100 \mathrm{~km} / \mathrm{h}$ and $130 \mathrm{~km} / \mathrm{h})$, steering angles in the clockwise and anti-clockwise direction (45 deg, $75 \mathrm{deg}, 100 \mathrm{deg}, 125 \mathrm{deg}$ and $150 \mathrm{deg}$ ) and road friction coefficient (0.3 and 1$)$.

The number of generated FLE rules was 256. For the second input group, three Gaussian membership functions (gaussmf) were employed for each input. The number of generated FLE rules was 216 and the NN were used to train ANFIS at 5 epochs.

\subsection{Kalman Filters}

The Kalman Filter is a mathematical tool that is used for stochastic estimation from noisy sensor measurements. Measured vehicle motion data includes a substantial quantity of noise and also, there are unobserved states in the system which must be estimated. For this reason different Kalman filtering techniques have been employed in this work.

The preliminary reconstruction of a sideslip angle from ANFIS-based observer is used as a "pseudo-measurement" in a Kalman Filter. This previous calculation presents the advantage of being a simple method which considers the system non-linarites and which gives good estimations.

\subsubsection{The process to be estimated}

The nonlinear system governed by the nonlinear stochastic difference equations can be written as:

$$
\begin{gathered}
x_{k+1}=f_{k}\left(x_{k}, u\right)+w_{k} \\
y_{k}=h_{k}\left(x_{k}, u\right)+v_{k}
\end{gathered}
$$


where $x_{k}$ represents the state vector, $\left[V_{y}, r\right]^{T}, u$ is the input, $[\delta], w_{k}$ the process noise vector, $y_{k}$ the measurement vector and $v_{k}$ the measurement noise vector. $w_{k}$ and $v_{k}$ are assumed to be white, zero mean and uncorrelated:

$$
\begin{gathered}
w_{k} \sim N\left(0, Q_{k}\right) \\
v_{k} \sim N\left(0, R_{k}\right)
\end{gathered}
$$

where $\mathrm{Q}$ and $\mathrm{R}$ are the covariance matrices describing the second-order properties of the state and measurement noise.

\subsubsection{Linear Kalman Filter}

Assuming that the system of section 3.2.1 is linear, then:

$$
\begin{gathered}
x_{k+1}=A x_{k}+B u+w_{k} \\
y_{k}=C x_{k}+v_{k}
\end{gathered}
$$

where matrices A and B are obtained, a linear tire model is considered:

$$
\begin{aligned}
A & =\left[\begin{array}{cc}
-\left(C_{f}+C_{r}\right) /\left(m V_{X}\right) & {\left[-\left(a C_{f}+b C_{r}\right) /\left(m V_{X}\right)\right.} \\
-\left(a C_{f}+b C_{r}\right) /\left(I_{Z Z} V_{X}\right) & -\left(a^{2} C_{f}+b^{2} C_{r}\right) /\left(I_{Z Z} V_{X}\right)
\end{array}\right] \\
B & =\left[\begin{array}{ll}
C_{f} / m & a C_{f} / I_{Z Z}
\end{array}\right] \\
C & =\left[\begin{array}{ll}
1 & 0 \\
0 & 1
\end{array}\right]
\end{aligned}
$$

The LKF (Linear Kalman Filter) is summarized as the following recursive equations:

1. The prediction of the state given by:

$$
\tilde{x}_{k \mid k-1}=A \tilde{x}_{k-1 \mid k-1}+B u_{k}
$$

2. The predicted error covariance is computed as:

$$
P_{k \mid k-1}=A P_{k-1 \mid k-1} A^{T}+Q
$$

3. The Kalman gain is calculated by:

$$
K_{x}=P_{k \mid k-1}+H^{T}\left[H P_{k \mid k-1} H^{T}+R\right]^{-1}
$$

4. The state estimation is updated with measurement $\mathrm{y}_{\mathrm{k}}$ :

$$
\tilde{x}_{k \mid k}=\tilde{x}_{k \mid k-1}+K_{k}\left[y_{k}-H \tilde{x}_{k \mid k-1}\right]
$$

5. The error covariance is updated:

$$
P_{k \mid k}=\left[I-K_{k} H\right] P_{k \mid k-1}
$$

\subsubsection{Extended Kalman Filter}


A Kalman Filter that linearizes in relation to the current mean and covariance is referred to as an Extended Kalman Filter (EKF).

The EKF is based on the assumption that a local linearization of the system may be a sufficient description of nonlinearity. Then, the system of section 3.2.1 can be described as:

$$
\begin{gathered}
x_{k+1}=A x_{k}+w_{k} \\
y_{k}=H x_{k}+v_{k}
\end{gathered}
$$

where $A$ is the Jacobian matrix of partial derivatives of $f(\cdot)$ with respect to $x$, that is:

$$
A_{i j}=\frac{\partial f_{i}}{\partial x_{i}}\left(x_{k}, u_{k}\right)
$$

$\mathrm{H}$ is the Jacobian matrix of $\mathrm{h}(\cdot)$ with respect to $\mathrm{x}$, that is:

$$
H_{i j}=\frac{\partial h_{i}}{\partial x_{i}}\left(x_{k}, u_{k}\right)
$$

and $\mathrm{f}($.$) are the equations of section 2$ assuming a non-linear tire model such as the Magic Formula of Pacejka [23].

The EKF (Extended Kalman Filter) is summarized as the following recursive equations:

6. The prediction of the state given by:

$$
\tilde{x}_{k \mid k-1}=f\left(\tilde{x}_{k-1 \mid k-1}, u_{k}\right)
$$

7. The predicted error covariance is computed as:

$$
P_{k \mid k-1}=A P_{k-1 \mid k-1} A^{T}+Q
$$

8. The Kalman gain is calculated by:

$$
K_{x}=P_{k \mid k-1}+H^{T}\left[H P_{k \mid k-1} H^{T}+R\right]^{-1}
$$

9. The state estimation is updated with measurement $y_{k}$ :

$$
\tilde{x}_{k \mid k}=\tilde{x}_{k \mid k-1}+K_{k}\left[y_{k}-h\left(\tilde{x}_{k \mid k-1}\right)\right]
$$

10. The error covariance is updated:

$$
P_{k \mid k}=\left[I-K_{k} H\right] P_{k \mid k-1}
$$

\subsubsection{Unscented Kalman Filter}

The basic premise behind the Unscented Kalman Filter (UKF) is that it is easier to approximate a Gaussian distribution than it is to approximate an arbitrary, nonlinear function. 
The nonlinear system governed by the nonlinear, stochastic difference equations can be written as:

$$
\begin{gathered}
x_{k+1}=f_{k}\left(x_{k}, u\right)+w_{k} \\
y_{k}=h_{k}\left(x_{k}, u\right)+v_{k}
\end{gathered}
$$

where $x_{k}$ represents the state vector, $\left[V_{y}, r\right]^{T}, u$ is the input, $[\delta], w_{k}$ the process noise vector, $y_{k}$ the measurement vector and $v_{k}$ the measurement noise vector. $w_{k}$ and $v_{k}$ are assumed to be white, zero mean and uncorrelated.

Consider propagating a random variable $x$ (dimension $\mathrm{n}$ ) through a function, $y$. Assume $x$ has mean $\tilde{x}$ and covariance $P_{x}$. To calculate the statistics of $y$, a matrix $X$ of $2 \mathrm{n}+1$ sigma vectors $X_{\mathrm{i}}$ (with corresponding weight $W_{i}$ ) is formed:

$$
\begin{gathered}
X_{0}=\tilde{x} \\
X_{i}=\tilde{x}+\left(\sqrt{(n+k) P_{x x}}\right)_{i} \quad i=1, \ldots \ldots, n \\
X_{i}=\tilde{x}-\left(\sqrt{(n+k) P_{x x}}\right)_{i} \quad i=n+1, \ldots \ldots, 2 n
\end{gathered}
$$

and the associated weights:

$$
\begin{gathered}
W_{0}^{(m)}=k /(n+k) \\
W_{i}^{(m)}=1 / 2(n+k) \quad i=1, \ldots \ldots, 2 n \\
W_{0}^{(c)}=k /(n+k)+\left(1-\alpha^{2}+\beta\right) \\
W_{i}^{(c)}=1 / 2(n+k) \quad i=1, \ldots \ldots, 2 n
\end{gathered}
$$

where $\left(\sqrt{(n+k) P_{x x}}\right)_{i}$ is the $i$-th row of column of the matrix square root of $(n+k) P_{x x}$ and $W_{i}$ is the weight which is associated with the $i$-th point. $k$ is a scaling parameter and is given by:

$$
k=\alpha^{2}(n+\varepsilon)-n
$$

where $\alpha$ is the distribution of the sampling points around the state mean, $\tilde{x}$, and is usually set to a small positive value and $\varepsilon$ is usually set to 0 . Parameter $\beta$ is used to incorporate prior knowledge of the distribution of $\tilde{x}$.

The UKF algorithm can be applied by restructuring the state vector, process and observation models. The state vector is augmented with the process and noise terms to give an $n_{a}=n+q$ dimensional vector:

$$
X_{k}^{a}=\left[\begin{array}{ll}
X_{k} & W_{k}
\end{array}\right]^{T}
$$

The process model is rewritten as a function of $X_{k}^{a}$ : 


$$
X_{k+1}=f\left[X_{k}^{a}, U_{k}\right]
$$

And the unscented transform uses $2 n^{a}+1$ sigma points to create:

- The augmented state estimation:

$$
\tilde{x}_{k \mid k}^{a}=\left(\begin{array}{c}
\tilde{x}_{k \mid k} \\
0_{q \times 1}
\end{array}\right)
$$

- The augmented covariance estimation:

$$
P_{k \mid k}^{a}=\left(\begin{array}{cc}
P_{k \mid k} & P_{(X W) k \mid k} \\
P_{(X W) k \mid k} & Q
\end{array}\right)
$$

The UKF (Unscented Kalman Filter) is summarized as the following recursive equations:

1. The set of sigma points, $W_{i}^{(c)}$ and $W_{i}^{(m)}$, are created and they are introduced to the augmented system.

2. The transformed set is given by instantiating each point through the process model:

$$
X_{i, k+1 \mid k}=f\left[X_{i, k \mid k}^{a}, U_{k}\right]
$$

3. The predicted mean is computed as:

$$
\tilde{x}_{k+1 \mid k}=\sum_{i=0}^{2 n^{a}} W_{i}^{(m)} \cdot X_{i, k+1 \mid k}^{a}
$$

4. The predicted covariance is computed as:

$$
P_{k+1 \mid k}=\sum_{i=0}^{2 n^{a}} W_{i}^{(c)} \cdot\left(X_{i, k+1 \mid k}-\tilde{x}_{k+1 \mid k}\right) \cdot\left(X_{i, k+1 \mid k}-\tilde{x}_{k+1 \mid k}\right)^{T}
$$

5. Instantiate each of the prediction points through the observation model:

$$
Y_{i, k+1 \mid k}=h\left[X_{i, k \mid k}^{a}, U_{k}\right]
$$

6. The predicted observation is calculated by:

$$
\tilde{y}_{k+1 \mid k}=\sum_{i=0}^{2 n} W_{i}^{(m)} \cdot Y_{i, k+1 \mid k}
$$

7. Since the observation noise is additive and independent, the innovation covariance is: 


$$
P_{(\xi \xi), k+1 \mid k}=R+\sum_{i=0}^{2 n^{a}} W_{i}^{(c)} \cdot\left(Y_{i, k+1 \mid k}-\bar{Y}_{k+1 \mid k}\right) \cdot\left(Y_{i, k+1 \mid k}-\bar{Y}_{k+1 \mid k}\right)^{T}
$$

8. The cross correlation matrix is determined by:

$$
P_{(X Y), k+1 \mid k}=R+\sum_{i=0}^{2 n^{a}} W_{i}^{(c)} \cdot\left(X_{i, k+1 \mid k}-\tilde{x}_{k+1 \mid k}\right) \cdot\left(X_{i, k+1 \mid k}-\tilde{x}_{k+1 \mid k}\right)^{T}
$$

9. The filter gain is calculated by:

$$
K_{k+1}=P_{(X Y), k+1 \mid k} P_{(\xi \xi), k+1 \mid k}^{-1}
$$

10. And the priori covariance:

$$
P_{k+1 \mid k+1}=P_{k+1 \mid k}-K_{k+1} P_{(\xi \xi), k+1 \mid k} K_{k+1}^{T}
$$

11. Finally, the state estimation is computed:

$$
\tilde{x}_{k+1 \mid k+1}=\tilde{x}_{k+1 \mid k}+K_{k+1}\left(Y_{k}-\bar{Y}_{k+1 \mid k}\right)
$$

\section{Results and discussion}

The proposed observer algorithm, based on ANFIS and a Kalman Filter, presented in this work has been validated using a typical C-class hatchback car, available in the CarSim library, having 205/55 R16 tires. Table 1 shows the hatchback vehicle parameters such as mass, wheel base, tire radius, and moments of inertia.

CarSim software is employed to test the effectiveness of the proposed algorithm [36]. Its use has become widespread as simulation software in the automotive industry as it combines traditional and modern multi-body vehicle dynamics, based on parametric modeling. This software also includes a three-part graphic database of a full-vehicle model, direction and speed control and external conditions, such as, road information, drag and so on.

In order to analyze the effect the sensor measurement noises have on the estimation of the sideslip angle, Gaussian noises with zero mean and variances of $0.01 \mathrm{deg}, 0.01 \mathrm{deg} / \mathrm{s}$ and $0.01 \mathrm{~m} / \mathrm{s}^{2}$ and $0.01 \mathrm{~km} / \mathrm{h}$ are added to $\delta$ (steering angle), $r$ (yaw rate), $a_{y}$ (lateral acceleration) and $\mathrm{V}_{\mathrm{x}}$ (longitudinal velocity), respectively, obtained from CarSim.

The performance of the sideslip angle observer has been proven in maneuvers with different road conditions; for example a double lane change maneuver of a vehicle travelling at 120 and $60 \mathrm{~km} / \mathrm{h}$ on a road surface with friction coefficients of 0.3 and 0.85 and a J-turn maneuver of a vehicle travelling at $120 \mathrm{~km} / \mathrm{h}$ on a road surface with friction coefficients of 0.5 and 0.85 Proof of the effectiveness of the proposed model was performed by means of a quantitative analysis that takes into consideration the error for the different accomplished excitation conditions. The following equation has been used to represent the norm error as a function of time [37]: 


$$
E_{t}=\frac{\varepsilon_{t}}{\sigma_{\beta}}
$$

where:

$$
\begin{aligned}
\varepsilon_{t}^{2} & =\int_{0}^{T}\left(\beta_{\text {CarSim }}-\beta_{\text {estimated }}\right)^{2} \\
\sigma_{\beta}^{2} & =\int_{0}^{T}\left(\beta_{\text {CarSim }}-\mu_{\text {beta }}\right)^{2}
\end{aligned}
$$

where $\beta_{\text {CarSim }}$ represents the measured sideslip angle obtained from CarSim, $\beta_{\text {estimated }}$ is the estimated sideslip angle and $\mu_{\text {beta }}$ is the mean value of the sideslip angle obtained from CarSim during the period $\mathrm{T}$.

shows the comparative results for the ANFIS-based observer (blue points) and ANFIS+UKF-based observer with lineal tire model (green points) for a double lane change maneuver for a vehicle travelling at $120 \mathrm{~km} / \mathrm{h}$ on a road surface of a friction coefficient of 0.85 . This figure demonstrates that the observer based only on ANFIS, shows undesirable behavior when noisy input data are considered. However, if the sideslip angle obtained from ANFIS is considered as input of UKF, the new obtained sideslip angle fits better with the real sideslip angle (red points). The norm error for the ANFIS-based observer is 0.58 . However, the norm error for the ANFIS+UKF-based observer is 0.31 . In the case of the yaw rate only being considered as observed data, the norm error for UKF-based observer is 2.77 and for EKF-based observer is 2.26.

shows the results for a double lane change maneuver for a vehicle travelling at $120 \mathrm{~km} / \mathrm{h}$ on a road surface of a friction coefficient of 0.3. The norm error for the ANFIS-based observer is 0.771 . However, the norm error for the ANFIS+UKF-based observer is 0.72 . In the case of the yaw rate only being considered as observed data, the norm error for the UKF-based observer is 7.122 and for the EKF-based observer it is 1.34.

The effectiveness of the proposed method for a J-turn maneuver for a vehicle travelling at $120 \mathrm{~km} / \mathrm{h}$ on a road surface of a friction coefficient of 0.85 (see ) is essentially similar to those obtained in the previous case. The norm error for the ANFIS-based observer is 2.284. However, the norm error for the ANFIS+UKF-based observer is 1.93. In case that yaw rate was only considered as observed data, the norm error for the UKF-based observer is 2.77 and for the EKF-based observer it is 2.26 .

From the results, we can conclude that the proposed ANFIS+UKF-based observer obtains a better estimation of the sideslip angle.

In order to demonstrate the improvement provided by the proposed observer, other Kalman-based observers with yaw rates and "pseudo-sideslip angles" as observer data were used for comparison purposes:

- Linear Kalman Filter with lineal tire model (ANFIS+LKF).

- Extended Kalman Filter with non-lineal tire model (ANFIS+EKF). 
It is worth highlighting that the performance of the ANFIS-based sideslip angle estimator has also been proven in maneuvers with different road conditions (see Table 2 and Table $3)$ :

- Double lane change (DLC) maneuver for a vehicle travelling at $120 \mathrm{~km} / \mathrm{h}$ on a pavement of a friction coefficient of 0.85 .

- DLC maneuver for a vehicle travelling at $120 \mathrm{~km} / \mathrm{h}$ on a pavement of a friction coefficient of 0.3 .

- DLC maneuver for a vehicle travelling at $60 \mathrm{~km} / \mathrm{h}$ on a pavement of a friction coefficient of 0.85 .

- J-turn maneuver for a vehicle travelling at $120 \mathrm{~km} / \mathrm{h}$ on a pavement of a friction coefficient of 0.85

- J-turn maneuver for a vehicle travelling at $120 \mathrm{~km} / \mathrm{h}$ on a pavement of a friction coefficient of 0.5

The norm and maximum errors are provided in Table 2 and Table 3, respectively. The norm error supplies information about the state response and the maximum error in relation to the transient response. It has been proven that a Kalman Filter is necessary to reduce the noisy measurements. Although all Kalman Filter-based observers have a good performance compared with ANFIS considered alone, the ANFIS+UKF-observer provides an equal or a better performance that the rest observers based on Kalman Filter (ANFIS+LKF and ANFIS+EKF). Similar results are obtained from observers based on ANFIS+LKF and ANFIS+EKF. In this case, the advantage of use the Extended Kalman Filter is not proved.

Additionally, the proposed observer is evaluated under a slalom maneuver (Figure 7) with a vehicle speed defined by a ramp function profile (from $10 \mathrm{~km} / \mathrm{h}$ to $120 \mathrm{~km} / \mathrm{h}$ in 120 seconds) and a sine sweep maneuver (Figure 8 ) at $80 \mathrm{~km} / \mathrm{h}$. Both tests are carried out on road surfaces of friction coefficients of 1, 0.5 and 0.2. Estimation results for slalom maneuver are shown in Figure 9 (a detail of results is shown in Figure 10). In Table 4 and Table 5, the norm and maximum errors are provided for slalom and sine sweep maneuvers, respectively. The proposed ANFIS+UKF-observer shows the smallest estimation error compared with the ANFIS-based and ANFIS+LKF-based observers.

Finally, two DLC tests are performed with different mass and suspension in order to show the sensitivity of the estimation process considering parameter uncertainty. Both tests are carried out on road surfaces of a friction coefficient of 0.5 and 0.85 , for a Double Lane Change test at $120 \mathrm{~km} / \mathrm{h}$. In the former case, it is considered an increase of $225 \mathrm{~kg}$ corresponding a weight of 3 persons. In the latter case, the suspension of C-class hatchback car (which originally had an independent suspension designed for a big car) is changed by an independent suspension designed for a small car. Table 6 represents the results. The variations induced by mass change are low. This can be explained as in the vehicle model, the mass change in the denominator is partially compensated for the force change in the numerator, as it is indicated in [38]. Concerning the suspension change, the results are very similar. It's worth keeping in mind the fact that the simple vehicle models for lateral dynamics do not consider the suspension effect. The proposed ANFIS+UKF-based observer is not affected by these parameters uncertainties. 


\section{Conclusion}

In this paper, the sideslip angle is estimated using a novel ANFIS+UKF estimator. The performance of recursive state estimation algorithms based on a Kalman Filter has been explored for sideslip angle estimation. The results indicate that the error in the estimation of sideslip angle decreases when a "pseudo-sideslip angle", is considered as observed data in the Kalman Filter.

The advantage of using an ANFIS-observer to calculate the "pseudo-sideslip angle" is the modeling of the non-linear vehicle dynamics, which requires sensor signals directly provided by vehicle sensors. The ANFIS-based estimator is better able to adapt in variable environments and learns by generalization. The Kalman Filter is suitable for reducing the noise measurements.

The model has been validated by means of a set of maneuvers that represent different driving and testing conditions. The ANFIS+UKF observer is more suitable for estimating the sideslip angle compared with other observers based on ANFIS and Kalman Filter such as Linear Kalman Filter (ANFIS+LKF) and Extended Kalman Filter (ANFIS+EKF). On the other hand, the proposed observer is not affected by parameter uncertainties such as suspension or vehicle mass.

The proposed method has been proven by means of CarSim software, which is a widespread and validated software employed in the automotive industry.

\section{Acknowledgements}

The authors gratefully acknowledge use of the services and facilities of the Research Institute of Vehicle Safety (ISVA) at Universidad Carlos III de Madrid, and the funds provided by the Regional Government of Madrid, through the research project CCG10UC3M/DPI-4614 and the Spanish Government through the CICYT project TRA201348030-C2-1-R.

\section{References}

[1] Boada, B.L., Boada, B.L. and Diaz, V. (2005). Fuzzy-Logic Applied to Yaw Moment Control for the Vehicle Stability. Vehicle System Dynamics. Vol.43 (10), pp. 753 - 770.

[2] Boada, M.J.L., Boada, B.L., Muñoz, A. and Diaz, V. (2006). An integrated control of front-wheel steering and front braking forces based on fuzzy logic. Proceedings of the Institution of Mechanical Engineers, Part D: Journal of Automobile Engineering. Vol. 220 (3), pp. 253 - 267.

[3] Guldner, J. and Utkin, V.I. (2000). The chattering problem in sliding mode systems. In Proc. 14th International Symposium of Mathematical Theory of Networks and Systems (MTNS'00).

[4] Park, K., Heo, S.-J. and Baek, I. (2001). Controller design for improving lateral vehicle dynamic stability. JSAE, vol. 22, pp. $481-486$.

[5] Ryu, J., Rossetter, J. and Gerdes, J.C. (2002). Vehicle slip and roll parameter estimation using GPS. 6th International Symp. Advance Vehicle Control (AVEC'02).

[6] Bevly, D.M., Ryu, J. and Gerdes, J.C. (2006). Integrating INS sensor with GPS measurements for continuous estimation of vehicle sideslip, roll and tire cornering stiffness. IEEE Transactions on Intelligent Transportation Systems, Vol. 7 (4), pp. 483 - 493.

[7] Ryan, J., Bevly, D. and Lu J. (2009). Robust sideslip estimation using GPS road grade sensing to replace a pitch rate sensor. Proceedings of the 2009 IEEE International Conference on Systems, Man and Cybernetics, pp. 2026 - 2031.

[8] Ungoren, A.Y., Peng, H. and Tseng, H.E. (2002) Experimental verification of lateral speed estimation methods. 6th International Symp. Advanced Vehicle Control (AVEC'02), (2002), pp. 361 - 366.

[9] Piyabongkarn, D., Rajamani, R., Grogg, J.A. and Lew, J.Y. (2009). Development and experimental evaluation of a 
slip angle estimator for vehicle stability control. IEEE Transactions on Control Systems Technology, Vol. 17 (1), pp. $78-88$.

[10] Doumiati, M., Victorino, A.C., Charara, A. and Lechner, D. (2011). Onboard real-time estimation of vehicle lateral tire-road forces and sideslip angle. IEEE/ASME Transaction on Mechatronics, Vol. 16 (4), pp. 601 - 614.

[11] Pi, D.W., Chen, N., Wang, J.X. and Zhang, B.J. (2011) Design and evaluation of sideslip angle observer for vehicle stability control. International Journal of Automotive Technology, Vol. 12 (3), pp. 391 - 399.

[12] Ungoren, A.Y. and Peng H. (2004). A study on lateral speed estimation methods. International Journal Vehicle Autonomous System, Vol. 2 (1/2), pp. 126 - 144.

[13] Stephant, J., Charara, A. and Meizel, D. (2004). Virtual sensor: Application to vehicle sideslip angle and transversal forces. IEEE Transactions on Industrial Electronic, Vol. 51 (2), pp. 278 - 289.

[14] Chung, T. and Yi, K. (2006). Design and evaluation of sideslip angle-based vehicle stability control scheme on a virtual test track. IEEE Transactions on Control Systems Technology, Vol. 14 (2), pp. 224 - 234.

[15] You, S.H., Hahn, J.-O. and Lee, H. (2009). New adaptive approaches to real time estimation of vehicle sideslip angle. Control Engineering Practice, Vol. 17, (2009), pp. 1367 - 1379.

[16] Chen, B.C. and Hsieh, F.C. (2008). Sideslip angle estimation using extended Kalman Filter. Vehicle System Dynamics, Vol. 46 Supplement, pp. 353 - 364.

[17] Hac, A., Nichols D. and Sygnarowicz, D. (2010). Estimation of vehicle roll angle and sideslip for crash sensing. SAE International: 2010 - 01 - 0529.

[18] Shenghui, P., Chuan, L., Menghe, L. and Lezhu, C. (2011). Virtual sensor for vehicle sideslip angle based on Extended Kalman Filter. 2011 Third International Conference on Measuring Technology and Mechatronics Automation.

[19] Gao, X., Yu, Z., Neubeck, J. and Wiedemann, J. (2010). Sideslip angle estimation based on input-output linearisation with tire-road friction adaption. Vehicle system Dynamics, Vol. 48 (2), pp. 217 - 234.

[20]Baffet, G., Charara, A. and Lechner, D. (2004). Estimation of vehicle sideslip, tire force and wheel cornering stiffness. Control Engineering Practice,Vol. 17 (11), pp. 1225 - 1264.

[21]Mariani S., Ghisi A. (2007). Unscented Kalman filtering for nonlinear structural dynamics. Nonlinear Dynamics, Vol. 49. pp. 131-150.

[22]Saurabh S. Bisht, S.S. and Singh, M.P. (2014). An adaptive unscented Kalman filter for tracking sudden stiffness changes. Mechanical Systems and Signal Processing. Vol. 49 (1-2), pp. 181-195.

[23]Davoodabadi I., Ramezani A.A., Mahmoodi-k M., Ahmadizadeh P. (2014). Identification of tire forces using Dual Unscented Kalman Filter algorithm. Nonlinear Dynamics, Vol. 78. pp. 1907-1919.

[24]Sharaf R., Taha, M.R., Tarbouchi, M. and Noureldin, A. (2007). Merits and limitations of using fuzzy inference system for temporal integration of INS/GPS in vehicular navigation. Soft Computing. Vol. 11 (9), pp 889-900.

[25]Noureldin, A., El-Shafie, A. and Taha, M. R. (2007). Optimizing neuro-fuzzy modules for data fusion of vehicular navigation systems using temporal cross-validation,” Eng. Appl. Artif. Intell. Vol. 20 (1), pp. 49-61.

[26]Nguyen-H, M. and Zhou. C. (2010). Improving GPS/INS Integration through Neural Networks. Journal of Telecommunications. Vol. 2 (2), pp 1-6.

[27]Saadeddina, K., Abdel-Hafezd, M.F., Jaradatb, M.A. and Jarrahd, M.A. (2013). Performance enhancement of lowcost, high-accuracy, state estimation for vehicle collision prevention system using ANFIS. Mechanical Systems and Signal Processing. Vol. 41 (1-2), pp 239-253.

[28]Du, H. and Zhang, N. (2011). Robust Vehicle Stability Control Based on Sideslip Angle Estimation. Robust Control, Theory and Applications, Prof. Andrzej Bartoszewicz (Ed.), ISBN: 978 - 953 - 307 - 229 - 6.

[29]Melzi, S. and Sabbioni, E. (2011). On the vehicle sideslip angle estimation through neural networks: Numerical and experimental results. Mechanical Systems and Signal Processing, Vol. 25, pp. 2005 - 2019.

[30]Boada B.L., Boada M.J.L., Gauchía A., Olmeda E. and Díaz V.(2015). Sideslip angle estimator based on ANFIS for vehicle handling and stability. Journal of Mechanical Science and Technology.Vol. 29 (4), pp 1473-1481.

[31]Loebis, D., Sutton, R., Chudley, J. and Naeem, W. (2004). Adaptive tuning of a Kalman filter via fuzzy logic for an intelligent AUV navigation system. Control Engineering Practice. Vol. 12 (12), pp. 1531-1539.

[32]Chatterjee, A. (2009). Differential evolution tuned fuzzy supervisor adapted extended Kalman filtering for SLAM problems in mobile robots. Robotica. Vol. 27 (3), pp. 411-423.

[33]Korniyenko, O.V., Sharawi, M.S. and Aloi D.N. (2005). Neural Network Based Approach for Tuning Kalman Filter. Proceedings of IEEE International Conference on Electro Information Technology; Lincoln, NE, USA. pp. 1-5.

[34]Cruz, P.P., Aquino, J.M. and Elizondo, M.R. (2004). Vector control using anfis controller with space vector modulation [induction motor drive applications]. In Universities Power Engineering Conference, 2004. UPEC 2004.

[35]Wei, J., Wei, M. and Zhao, W. (2011). Study on soft computing arithmetic for vehicle yaw rate based on ANFIS. International Journal of Vehicle Design, Vol. 56 (1/2/3/4), (2011), pp. 146 - 160.

[36] CarSim (2014) http://www.carsim.com/ (2014)

[37]Boada, M.J.L., Calvo, J.A., Boada B.L., and Díaz, V. (2011). Modeling of a magnetorheological damper by recursive lazy learning. International Journal of Non-Linear Mechanics. Vol. 46, № 3, pp. 479-485. 
[38] Baffet, G., Charara, A. and Lechner, D. (2009). Estimation of vehicle sideslip, tire force and wheel cornering stiffness. Control Engineering Practice. Vol. 17 (11), pp. 1255-1264.

\section{List of Figures}

Figure 1. Observer architecture

Figure 2. Architecture of an ANFIS equivalent to a first-order Sugeno fuzzy model with three inputs

Figure 3. ANFIS learning process

Figure 4. Results for a double lane change maneuver for a vehicle travelling at $120 \mathrm{~km} / \mathrm{h}$ on a pavement of friction coefficient of 0.85 (blue points: ANFIS, green points: ANFIS+UKF, red points: CarSim).

Figure 5. Results for a double lane change maneuver for a vehicle travelling at $120 \mathrm{~km} / \mathrm{h}$ on a pavement of friction coefficient of 0.3 (blue points: ANFIS, green points: ANFIS+UKF, red points: CarSim).

Figure 6. Results for a J-turn maneuver for a vehicle travelling at $120 \mathrm{~km} / \mathrm{h}$ on a pavement of friction coefficient of 0.85 (blue points: ANFIS, green points: ANFIS+UKF, red points: CarSim)

Figure 7. Slalom maneuver

Figure 8. Sine sweep maneuver

Figure 9. Results for a slalom maneuver for a vehicle travelling with a speed defined by a ramp on a pavement of friction coefficient of 1 (blue points: ANFIS, green points: ANFIS $+\mathrm{UKF}$, red points: CarSim)

Figure 10. Detail of Figure 9 (blue points: ANFIS, green points: ANFIS+UKF, red points: CarSim)

\section{List of Tables}

Table 1. Vehicle parameters for the C-Class hatchback car

Table 2. Error norms for sideslip angle estimators for Change Lane and J-turn maneuvers

Table 3. Maximum errors for sideslip angle estimators for Change Lane and J-turn maneuvers

Table 4. Error norms and maximum error for a slalom test with a ramp speed

Table 5. Error norms and maximum error for a sine sweep test with at $80 \mathrm{~km} / \mathrm{h}$

Table 6. DLC test at $120 \mathrm{~km} / \mathrm{h}$, robustness to vehicle mass and suspension: error norms and maximum errors for sideslip angle ANFIS+UKF-based estimator 
Table 1. Vehicle parameters for the C-Class hatchback car

\begin{tabular}{|c|c|c|c|}
\hline Symbol & Description & Value & Unit \\
\hline $\mathrm{m}_{\mathrm{s}}$ & Sprung mass & 1274 & $\mathrm{~kg}$ \\
\hline $\mathrm{m}_{\mathrm{u}}$ & Unsprung mass & 142 & $\mathrm{~kg}$ \\
\hline $\mathrm{I}_{\mathrm{xx}}$ & Roll inertia & 606.1 & $\mathrm{~kg} \cdot \mathrm{m}^{2}$ \\
\hline $\mathrm{I}_{\mathrm{vy}}$ & Pitch inertia & 1523 & $\mathrm{~kg} \cdot \mathrm{m}^{2}$ \\
\hline $\mathrm{I}_{\mathrm{zz}}$ & Yaw inertia & 1523 & $\mathrm{~kg} \cdot \mathrm{m}^{2}$ \\
\hline $\mathrm{a}$ & Distance from front tire to COG & 1016 & $\mathrm{~mm}$ \\
\hline $\mathrm{b}$ & Distance from rear tire to COG & 1562 & $\mathrm{~mm}$ \\
\hline $\mathrm{R}_{\mathrm{w}}$ & Effective rolling radius & 310 & $\mathrm{~mm}$ \\
\hline $\mathrm{H}$ & Height of COG & 540 & $\mathrm{~mm}$ \\
\hline $\mathrm{T}$ & Wheel track & 1539 & - \\
\hline $\mathrm{K}_{\mathrm{s}}$ & Steering ratio & $17.5: 1$ & $\mathrm{~N} / \mathrm{rad}$ \\
\hline $\mathrm{C}_{\mathrm{f}}$ & Front tire cornering stiffness & 125167 & $\mathrm{~N} / \mathrm{rad}$ \\
\hline $\mathrm{C}_{\mathrm{r}}$ & Rear tire cornering stiffness & 125167 & \\
\hline
\end{tabular}

Table 2. Error norms for sideslip angle estimators for Change Lane and J-turn maneuvers

\begin{tabular}{|l|c|c|c|c|c|}
\hline & \multicolumn{5}{|c|}{$\mathrm{E}_{\mathrm{t}}$} \\
\hline & $\begin{array}{c}\mathrm{DLC} \text { at } 120 \mathrm{~km} / \mathrm{h} \\
\text { and friction } \\
\text { coefficient of } \\
0.85\end{array}$ & $\begin{array}{c}\text { DLC at } 120 \mathrm{~km} / \mathrm{h} \\
\text { and friction } \\
\text { coefficient of } \\
0.3\end{array}$ & $\begin{array}{c}\mathrm{DLC} \text { at } 60 \mathrm{~km} / \mathrm{h} \\
\text { and friction } \\
\text { coefficient of } \\
0.85\end{array}$ & $\begin{array}{c}\text { J-turn at } 120 \\
\mathrm{~km} / \mathrm{h} \text { and } \\
\text { friction } \\
\text { coefficient of } \\
0.85\end{array}$ & $\begin{array}{c}\text { J-turn at } 120 \\
\mathrm{~km} / \mathrm{h} \text { and } \\
\text { friction } \\
\text { coefficient of } \\
0.5\end{array}$ \\
\hline ANFIS & 0.58 & 0.771 & 0.679 & 2.284 & 2.43 \\
\hline ANFIS+LKF & 0.46 & 0.7 & 0.482 & 1.89 & 2.01 \\
\hline ANFIS+EKF & 0.46 & 0.7 & 0.48 & 1.89 & 2.01 \\
\hline ANFIS+UKF & 0.31 & 0.72 & 0.269 & 1.93 & 2.09 \\
\hline
\end{tabular}

Table 3. Maximum errors for sideslip angle estimators for Change Lane and J-turn maneuvers

\begin{tabular}{|l|c|c|c|c|c|}
\hline & \multicolumn{5}{|c|}{$\mathrm{E}_{\max }$ (rad) } \\
\hline & $\begin{array}{c}\text { DLC at } 120 \mathrm{~km} / \mathrm{h} \\
\text { and friction } \\
\text { coefficient of } \\
0.85\end{array}$ & $\begin{array}{c}\text { DLC at } 120 \mathrm{~km} / \mathrm{h} \\
\text { and friction } \\
\text { coefficient of } \\
0.3\end{array}$ & $\begin{array}{c}\text { DLC at } 60 \mathrm{~km} / \mathrm{h} \\
\text { and friction } \\
\text { coefficient of } \\
0.85\end{array}$ & $\begin{array}{c}\text { J-turn at } 120 \\
\mathrm{~km} / \mathrm{h} \text { and } \\
\text { friction } \\
\text { coefficient of } \\
0.85\end{array}$ & $\begin{array}{c}\text { J-turn at } 120 \\
\mathrm{~km} / \mathrm{h} \text { and } \\
\text { friction } \\
\text { coefficient of } \\
0.5\end{array}$ \\
\hline ANFIS & 0.049 & 0.12 & 0.0354 & 0.04 & 0.171 \\
\hline ANFIS+LKF & 0.033 & 0.076 & 0.022 & 0.0363 & 0.106 \\
\hline ANFIS+EKF & 0.033 & 0.075 & 0.022 & 0.0363 & 0.1062 \\
\hline ANFIS+UKF & 0.016 & 0.032 & 0.016 & 0.022 & 0.019 \\
\hline
\end{tabular}

Table 4. Error norms and maximum error for a slalom test with a ramp speed

\begin{tabular}{|c|c|c|c|c|c|c|}
\hline & \multicolumn{2}{|c|}{ Friction coefficient of 1 } & \multicolumn{2}{c|}{ Friction coefficient of 0.5 } & \multicolumn{2}{c|}{ Friction coefficient of $\mathbf{0 . 2}$} \\
\cline { 2 - 7 } & $\mathbf{E}_{\mathbf{t}}$ & $\mathbf{E}_{\max }(\mathbf{r a d})$ & $\mathbf{E}_{\mathbf{t}}$ & $\mathbf{E}_{\max }(\mathbf{r a d})$ & $\mathbf{E}_{\mathbf{t}}$ & $\mathbf{E}_{\max }(\mathbf{r a d})$ \\
\hline ANFIS & 0.83 & 0.3 & 1.01 & 0.21 & 5.3 & 0.52 \\
\hline ANFIS+LKF & 0.69 & 0.13 & 0.85 & 0.14 & 4.3 & 0.46 \\
\hline ANFIS+UKF & 0.44 & 0.07 & 0.63 & 0.07 & 2.76 & 0.24 \\
\hline
\end{tabular}

Table 5. Error norms and maximum error for a sine sweep test with at $80 \mathrm{~km} / \mathrm{h}$

\begin{tabular}{|c|c|c|c|c|c|c|}
\hline & \multicolumn{2}{|c|}{ Friction coefficient of 1 } & \multicolumn{2}{c|}{ Friction coefficient of 0.5 } & \multicolumn{2}{c|}{ Friction coefficient of $\mathbf{0 . 2}$} \\
\cline { 2 - 7 } & $\mathbf{E}_{\mathbf{t}}$ & $\mathbf{E}_{\max }(\mathbf{r a d})$ & $\mathbf{E}_{\mathbf{t}}$ & $\mathbf{E}_{\max }(\mathbf{r a d})$ & $\mathbf{E}_{\mathbf{t}}$ & $\mathbf{E}_{\max }(\mathbf{r a d})$ \\
\hline ANFIS & 6.05 & 0.049 & 6.81 & 0.049 & 9.41 & 0.049 \\
\hline ANFIS+LKF & 4.13 & 0.03 & 4.63 & 0.030 & 6.40 & 0.030 \\
\hline ANFIS+UKF & 2.025 & 0.008 & 2.14 & 0.008 & 2.55 & 0.007 \\
\hline
\end{tabular}


Table 6. DLC test at $120 \mathrm{~km} / \mathrm{h}$, robustness to vehicle mass and suspension: error norms and maximum errors for sideslip angle ANFIS+UKF-based estimator

\begin{tabular}{|c|c|c|c|c|c|c|}
\hline & \multicolumn{3}{|c|}{ Friction coefficient of 0.85} & \multicolumn{3}{c|}{ Friction coefficient of 0.5} \\
\cline { 2 - 7 } & $\begin{array}{c}\text { Vehicle with } \\
\text { initial } \\
\text { conditions }\end{array}$ & $\begin{array}{c}\text { Increase of } \\
\text { weight: } \\
\mathrm{m}+225 \mathrm{~kg}\end{array}$ & $\begin{array}{c}\text { Suspension of } \\
\text { a small car }\end{array}$ & $\begin{array}{c}\text { Vehicle with } \\
\text { initial } \\
\text { conditions }\end{array}$ & $\begin{array}{c}\text { Increase of } \\
\text { weight: } \\
\mathrm{m}+225 \mathrm{~kg}\end{array}$ & $\begin{array}{c}\text { Suspension of } \\
\text { a small car }\end{array}$ \\
\hline $\mathbf{E}_{\mathbf{t}}$ & 0.31 & 0.34 & 0.35 & 0.3 & 0.43 & 0.32 \\
\hline $\mathbf{E}_{\max }(\mathbf{r a d})$ & 0.016 & 0.016 & 0.016 & 0.016 & 0.016 & 0.016 \\
\hline
\end{tabular}


Figure 1

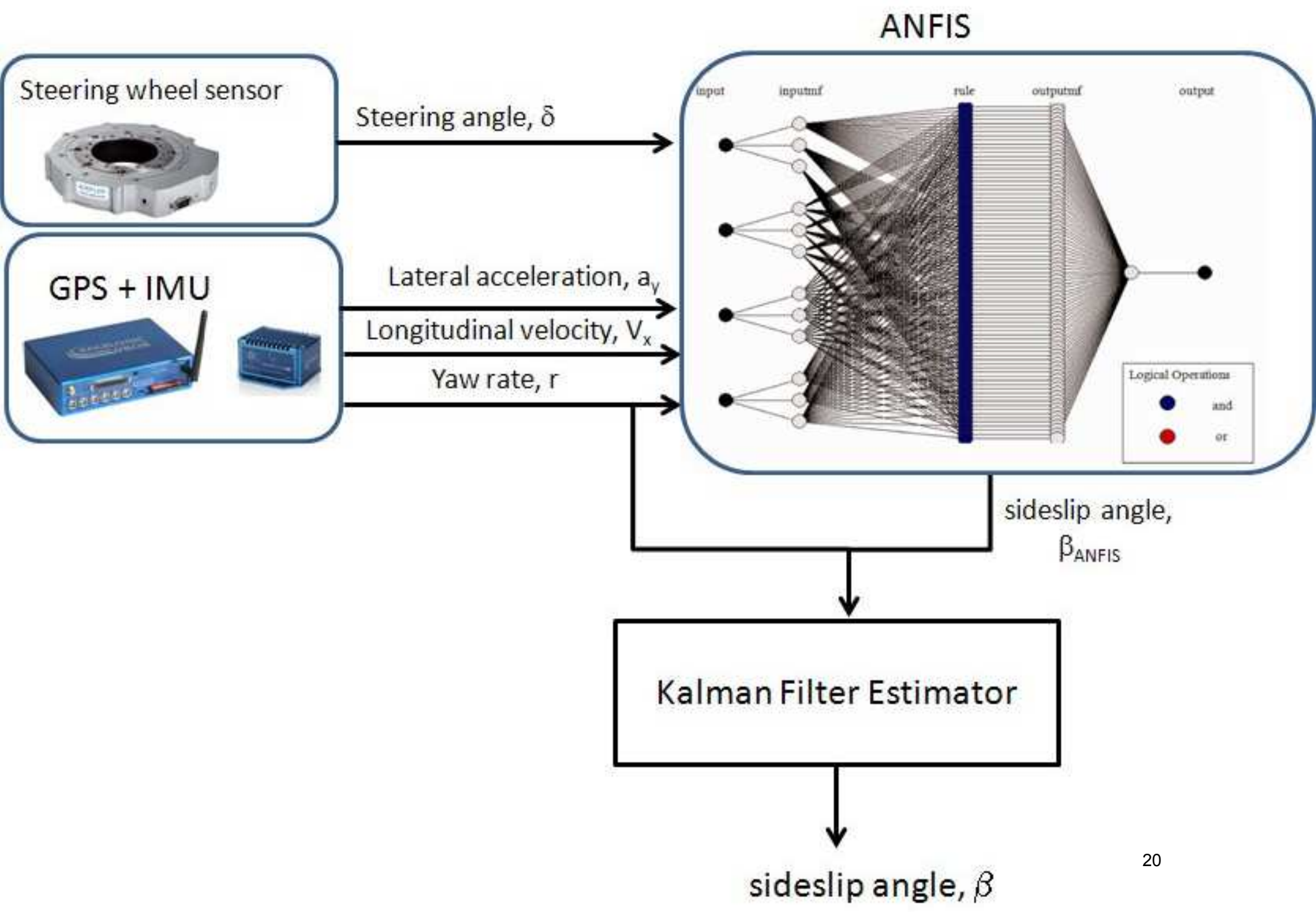


Figure 2

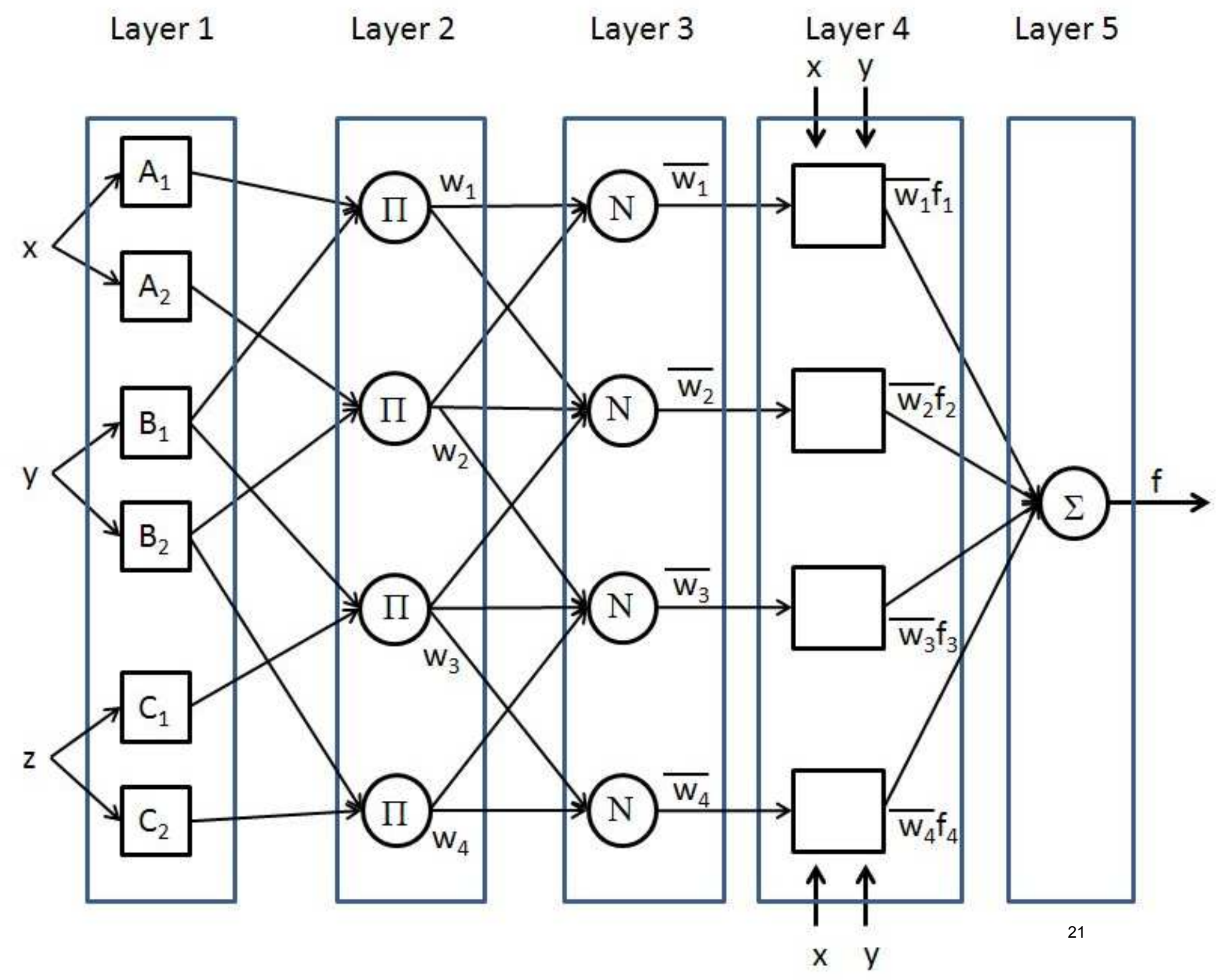




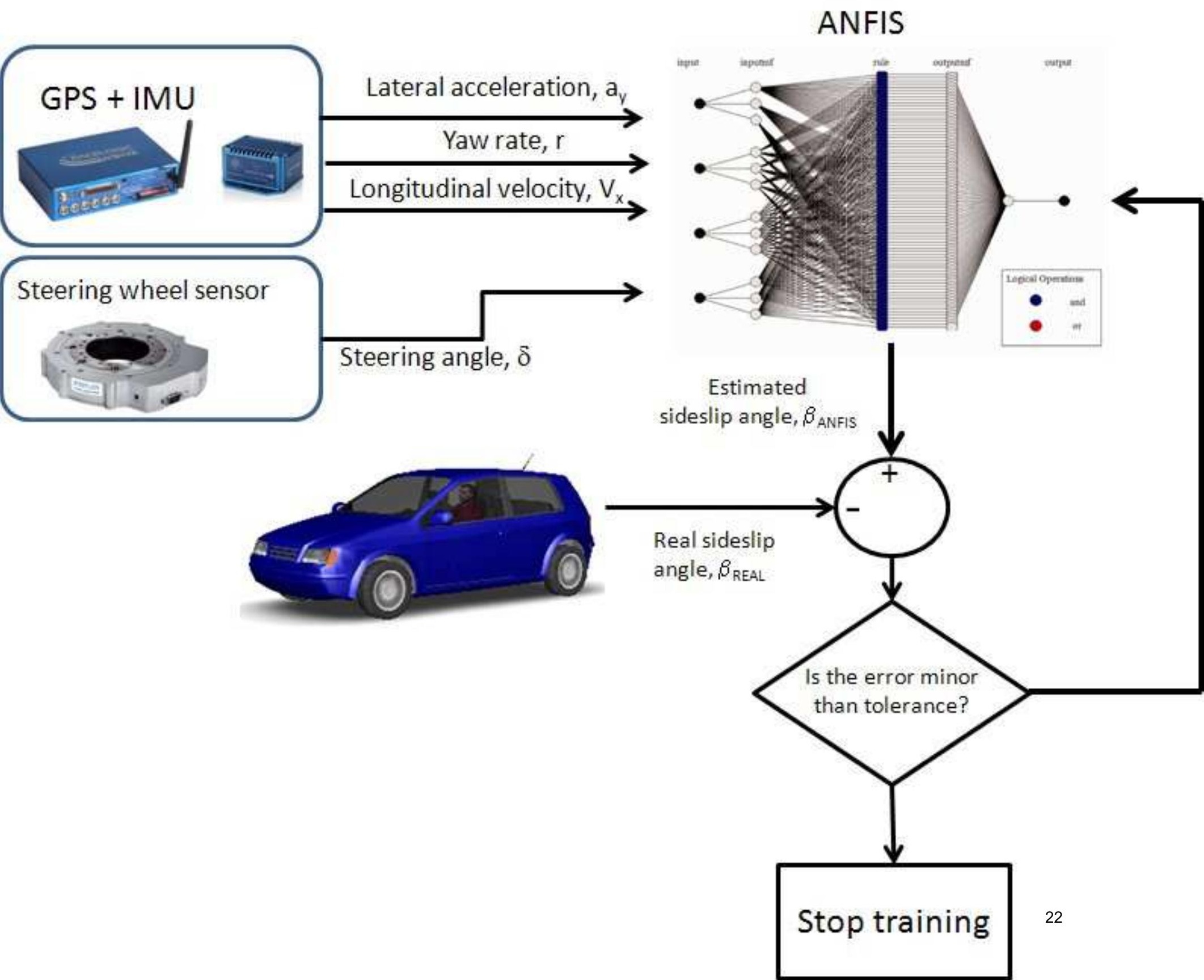


Figure 4

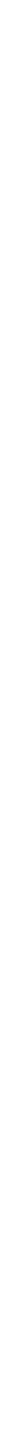

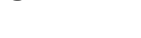




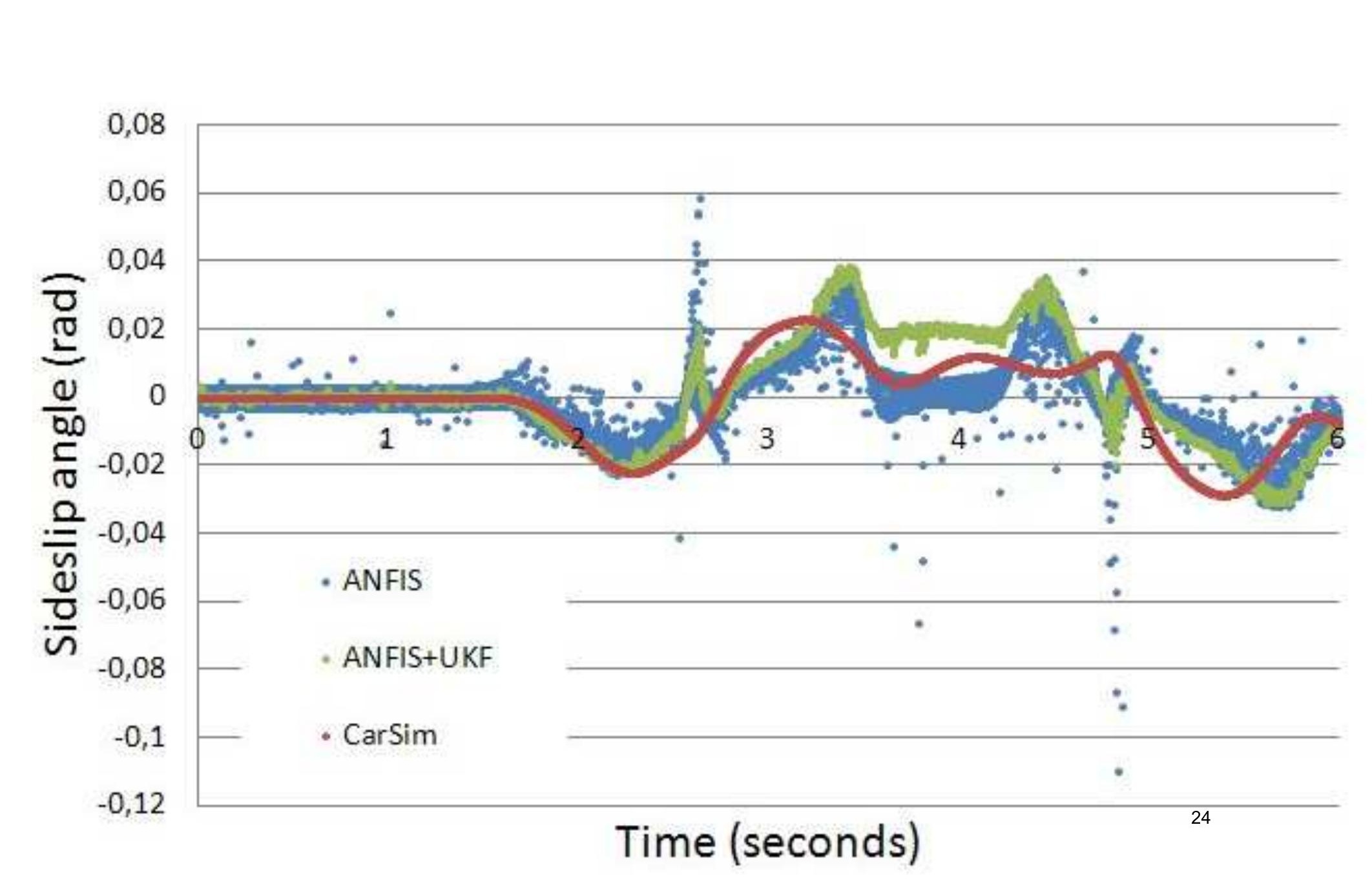

Figure 5

\section{-}

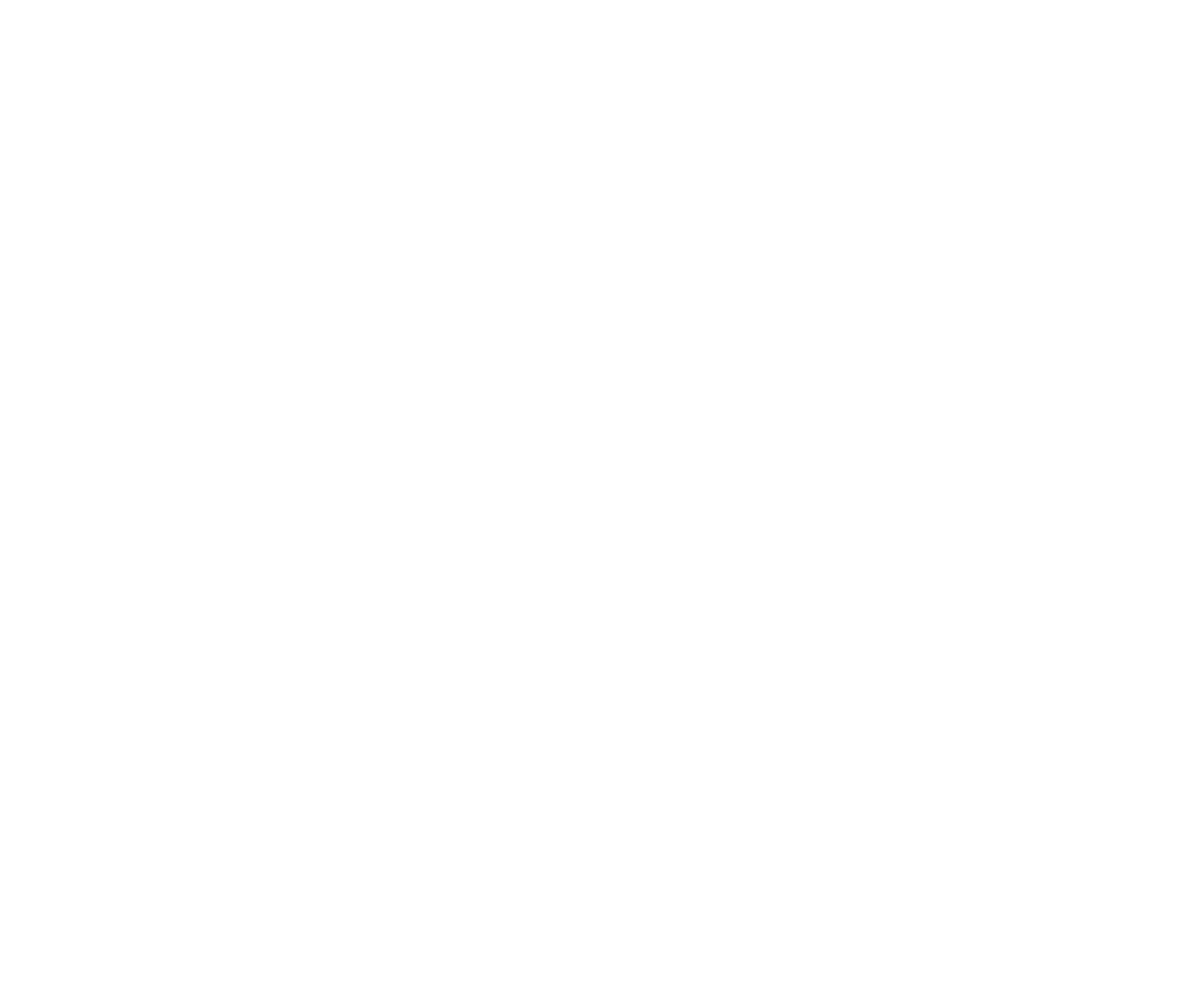

\section{1
-1}




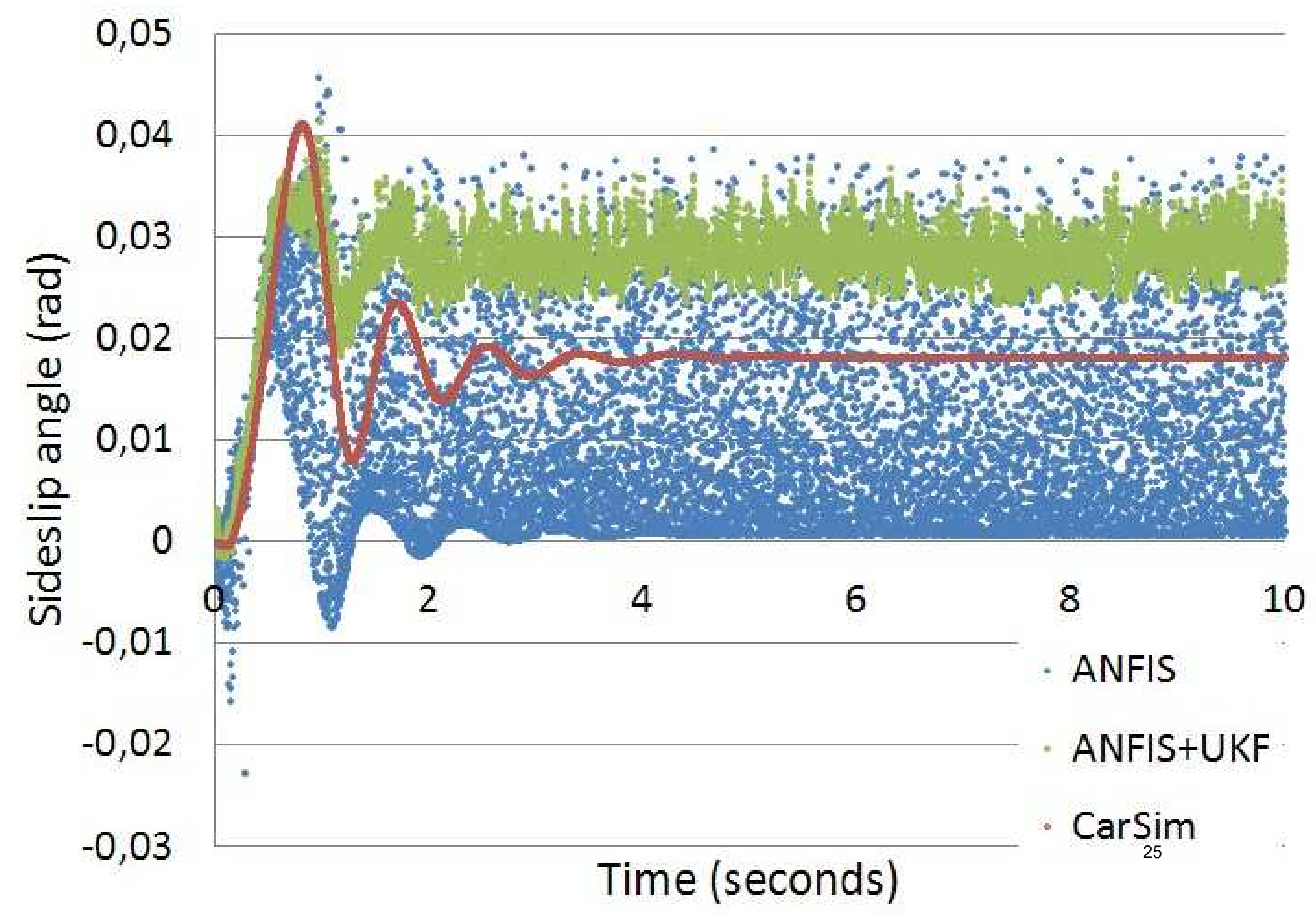


Figure 7

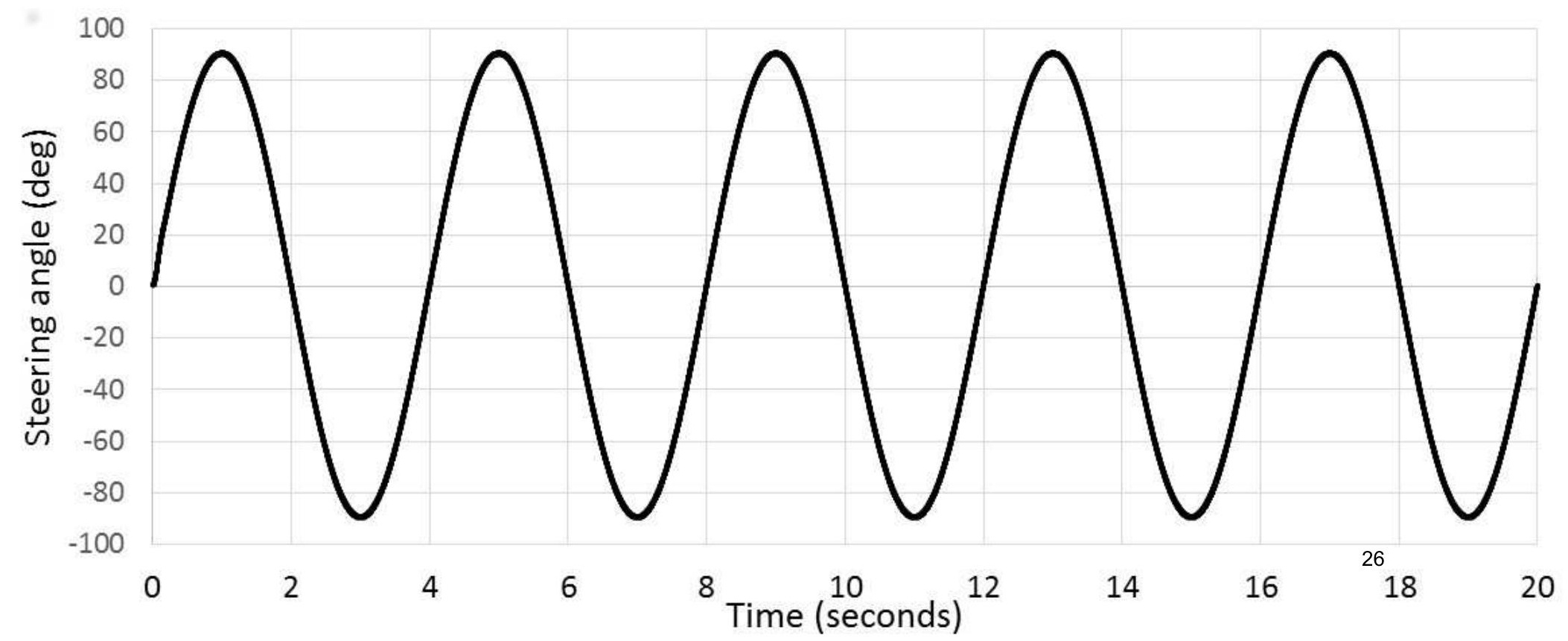





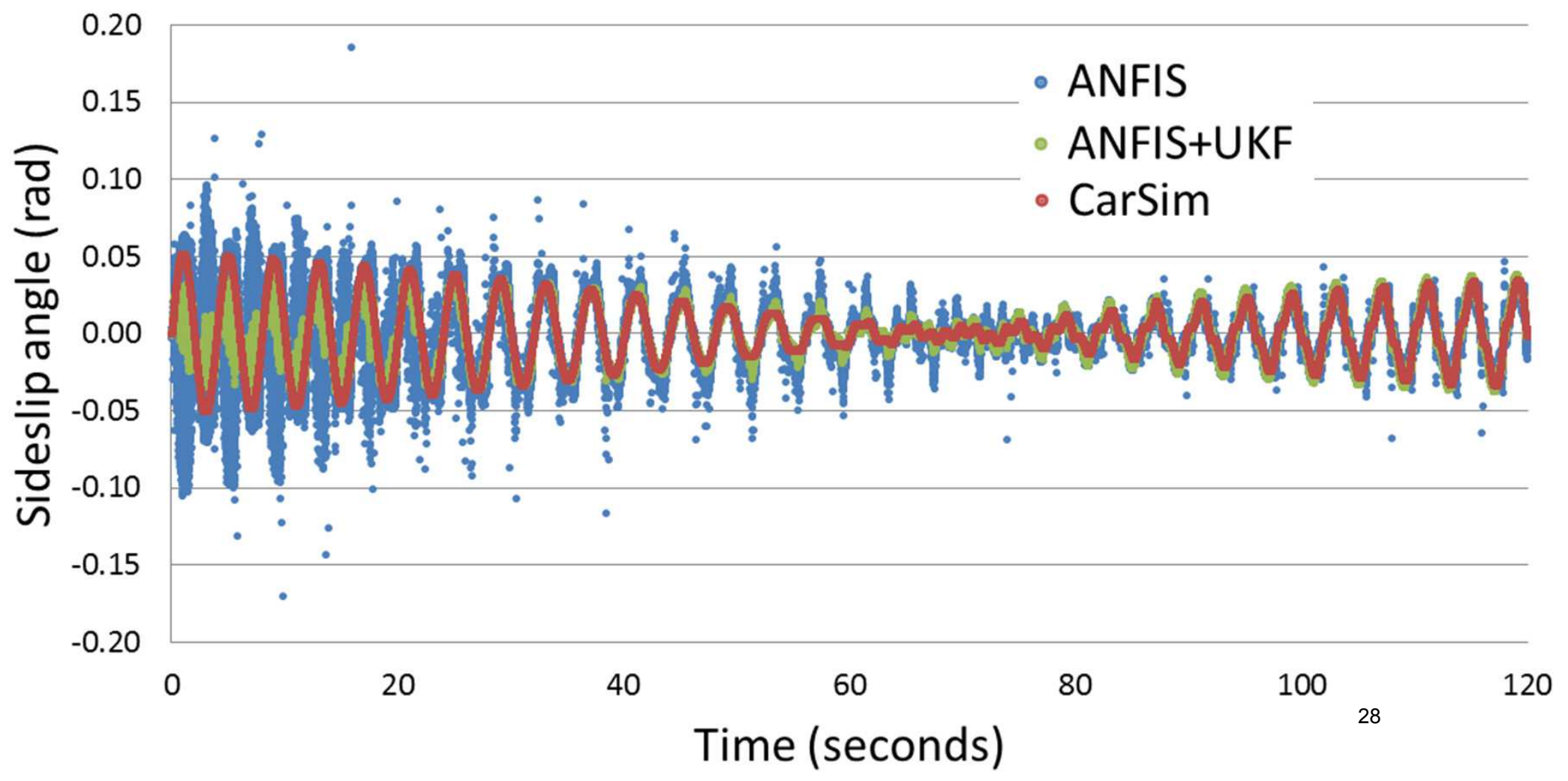




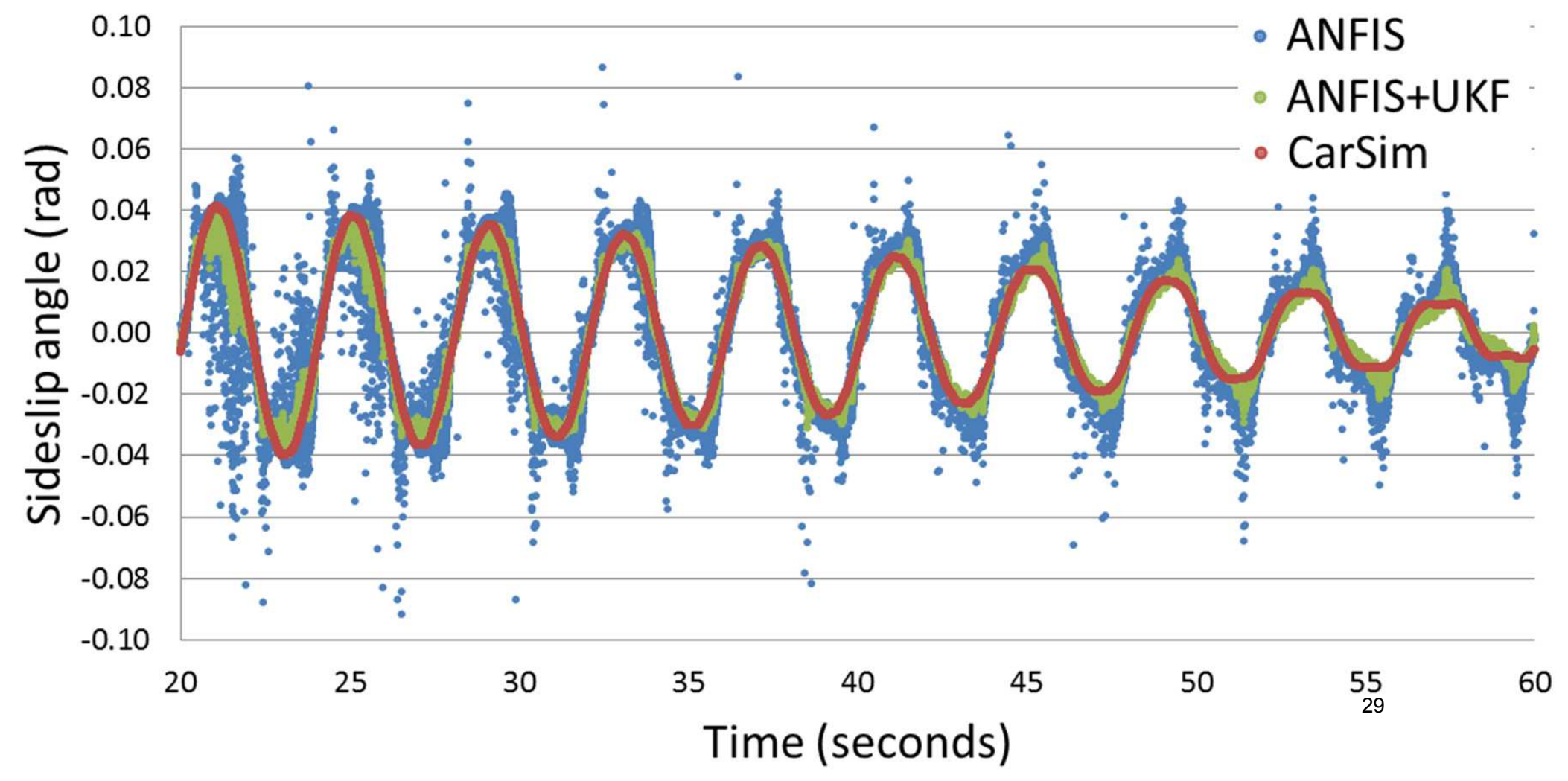

